
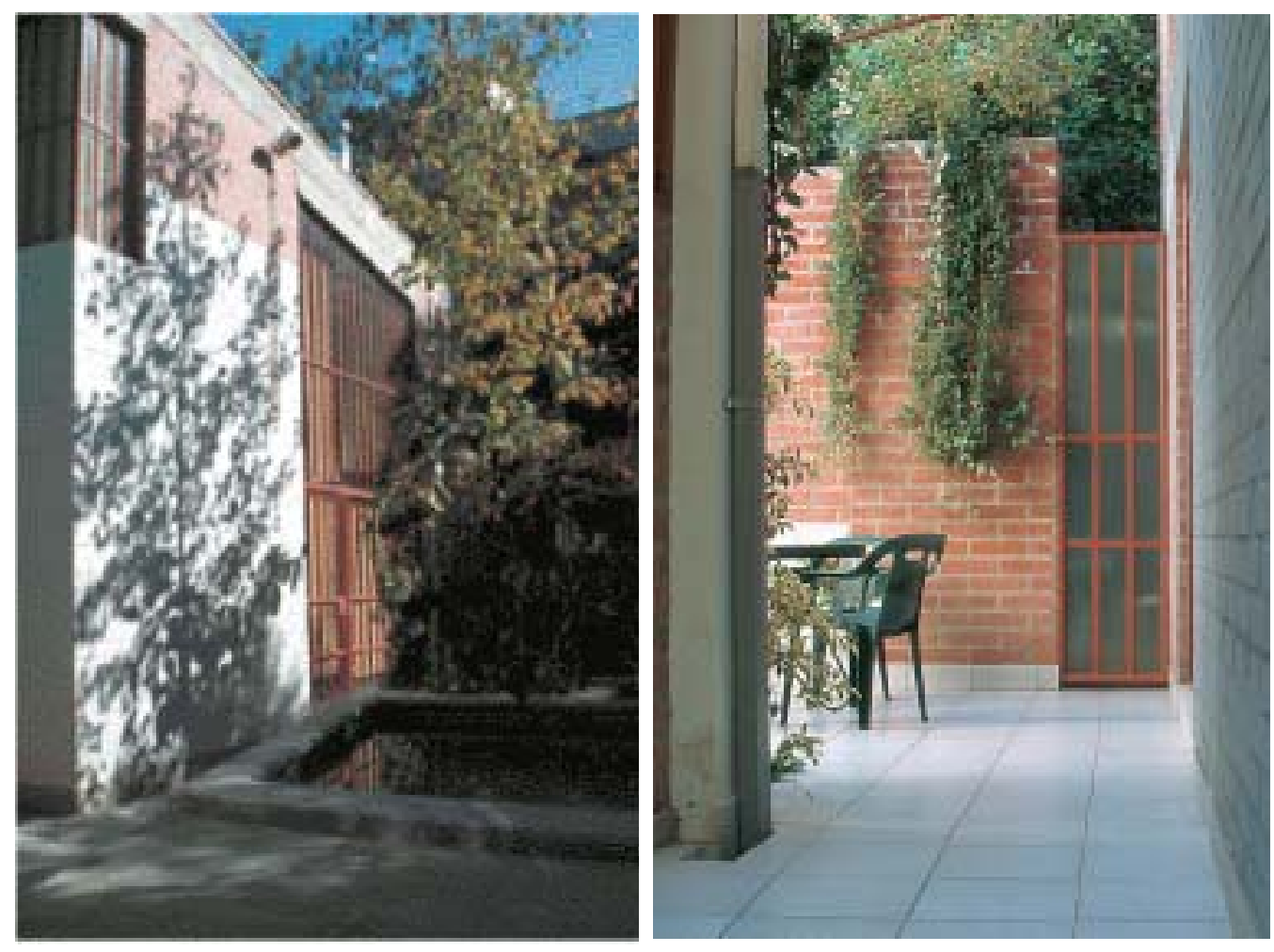

Por

Neil Kerestegian

Ubicación

Roberto del Río 1774, Providencia

Construcción

Neil Kerestegian

Materialidad principal

Alb añilería de lad rillo

Superficie terreno

$620 \mathrm{~m}^{2}$

Superficie construida

$350 \mathrm{~m}^{2}$

Fecha construcción

1999

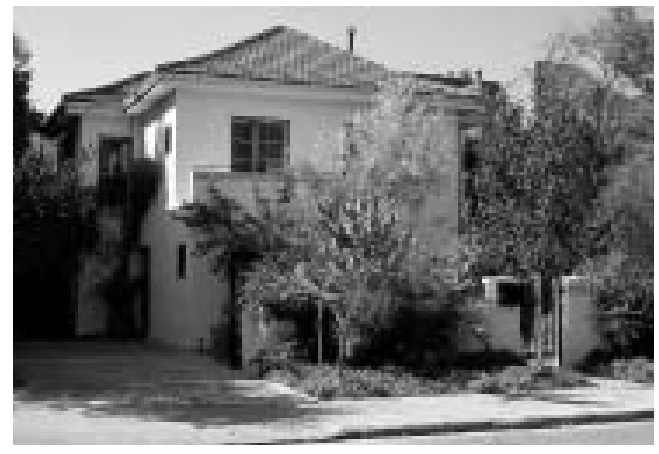

\title{
Casa Kerestegian
}

Un lugar irreverente donde vivir es una respuesta a una ciudad irreverente. Imposible controlar lo que pasa con el exterior: sol, vistas, uso del suelo, destino, son cosas que nos sobrepasan. Pero si queremos estar en un lugar urbano que podamos identificar como lo más ciudad posible y con suelo propio teníamos que decidir quedarnos donde estábamos y con ingenio hacer de las desventajas, ventajas.

No podemos estar como perpetuos nómades emigrando en busca de lugares utópicos inexistentes. Nada queríamos saber con estar marginados en una parcela en los contornos de la ciudad, ni en uno de los nuevos barrios asépticos con nombres encantadores de villas exóticas o autóctonas o nombres pomposos de Don o Doña o quizás de San o Santa tal o cual, ni menos encumbrados y ahogados en un departamento cohabitando con otros inquilinos por arriba, por abajo y por los lados. Nos bastaba con esta antigua casa de Costábal y Garafulic, que ha sido la excusa para instalarnos de una manera distinta, reverente sólo con las necesidades de los que habitamos en ella. A la antigua casa se le sumó un taller de aproximadamente $125 \mathrm{~m}^{2}$ en una planta de $8.5 \times 10 \mathrm{~m}$, más un segundo nivel en balcón sobre la doble altura.
En total, casa y taller tienen alrededor de $350 \mathrm{~m}^{2}$ útiles en un terreno de $620 \mathrm{~m}^{2}$. Los espacios exteriores se han transformado en patios y pasadizos entre muros y vegetación. Muros y árboles se han colocado de manera de aislarse de las construcciones vecinas.

Al final, todo tiende a remarcar la interioridad y a evocar un lugar extraño mezcla de cité chileno con reciclaje sajón, andaluz y laberinto medieval italiano en plena comuna de Providencia, a pasos de Pocuro y Bilbao. Tal situación no resistiría una crítica ortodoxa típica del proyecto de arquitectura en que la obra se entiende más bien como un todo completo y acabado. Aquí, en cambio, la obra no es más que una diversión y en la cual nada tiene asegurado una temporalidad mayor que la paciencia o necesidades de sus usuarios.

Se tomó la precaución de mantener una espina dorsal central de máxima longitud visual uniendo una sucesión de ventanas desde la calle hasta más allá del fondo del terreno que pasan de exteriores a interiores varias veces en un juego diurno y nocturno de iluminaciones, en un trayecto que sobrepasa los $100 \mathrm{~m}$ lineales.

Un patio central circundado en tres costados por muros de dos pisos de altura con una abertura 

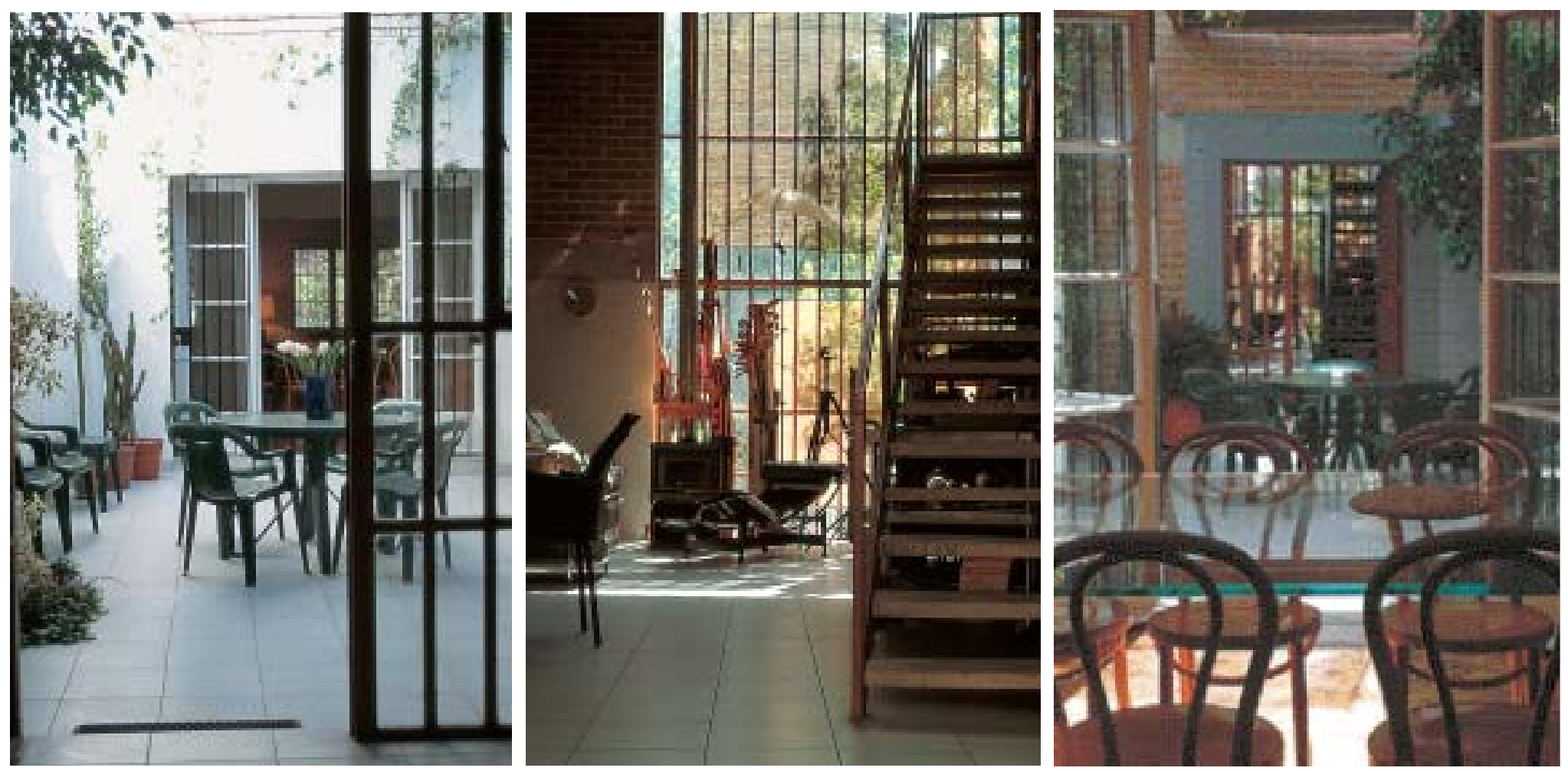

lateral que separa la casa del taller uniéndola solamente en el segundo piso, a través de un puente cerrado y por el cuarto lado norte por un muro pileta jardinera y una membrana vegetal de enredaderas y árboles, que en alturas escalonadas aíslan y amortiguan de un edificio colindante de cuatro pisos, probablemente uno de los peores de la comuna. Este patio se ha transformado casi en un espacio interior y de intenso uso, sobre todo en las noches veraniegas, integrándose como prolongación y unión visual y física con el estar y comedor de la casa y el doble espacio del taller, conformando una especie de galería que une diversas actividades que se desarrollan simultáneamente.

Neil Kerestegian

Ha trabajado como arquitecto, diseñador, escultor y profesor en la Facultad de Arquitectura, Diseño y Estudios Urbanos de la Pontifici Universidad Católica de Chile.
museos y bienales nacionales.

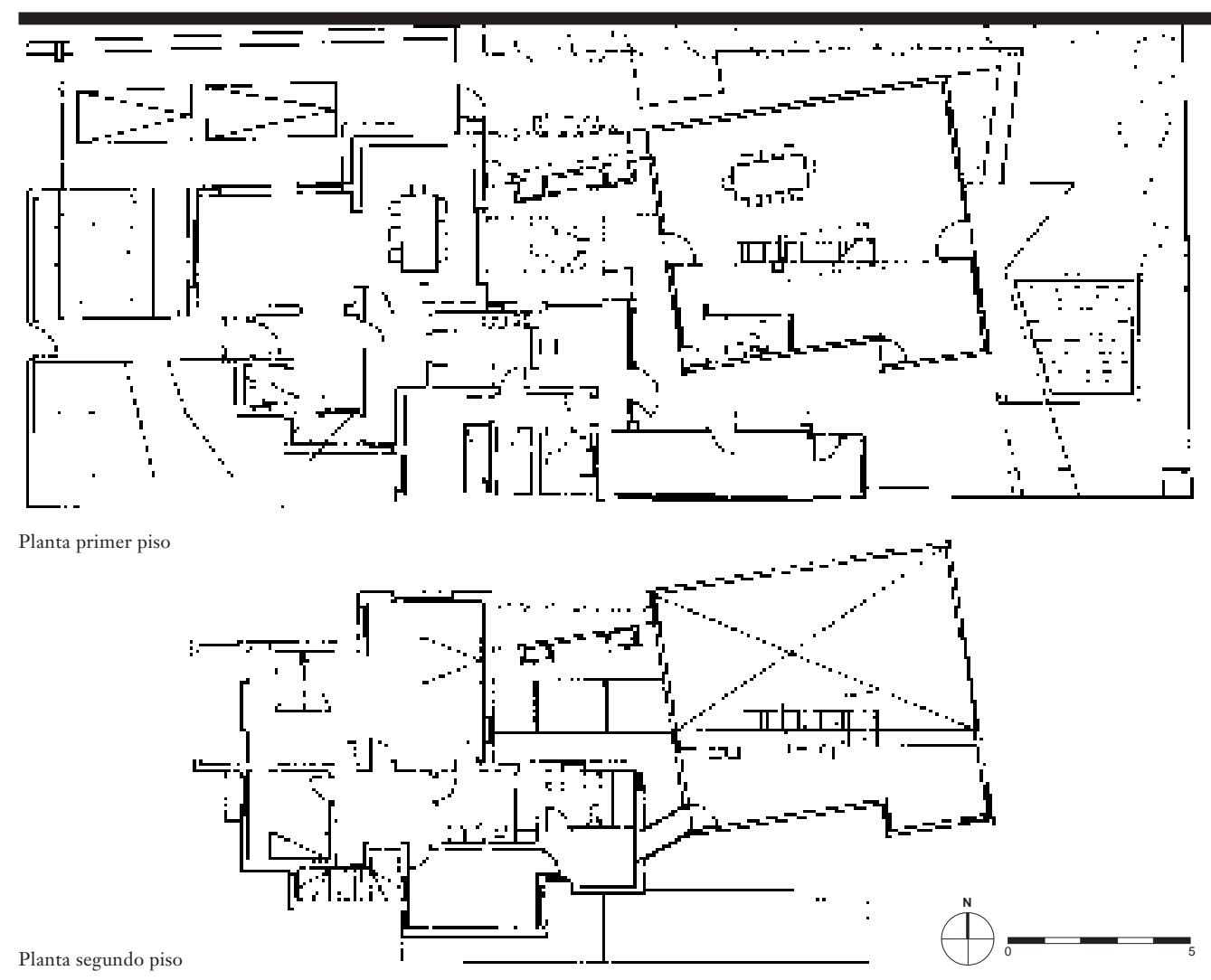

